\title{
Microwave heating of water-ethanol mixtures
}

\author{
Alberto Schiraldi ${ }^{1}\left[\right.$ Alberto Paoli $^{1}$ \\ Received: 25 March 2021 / Accepted: 10 September 2021 \\ (c) The Author(s) 2021
}

\begin{abstract}
A simple measure of the susceptibility of a substance to microwaves (MW) is the resulting heating rate that depends on its heat capacity, density, starting temperature, MW extinction coefficient at the used MW frequency and distance from the irradiated surface. Water, that is ubiquitous in many products, currently treated with MW, shows a large susceptibility at $2450 \mathrm{MHz}$ MW. This is why water is a suitable reference to rank the MW susceptibility of other compounds. Aqueous solutions are the simplest systems to investigate how the presence of extra compounds can modify (normally, reduce) this property. The present work provides a very simple evidence of a peculiar MW susceptibility of the water-ethanol mixture with azeotropic composition, $X_{\mathrm{EtOH}}=0.90 \mathrm{~mol}$ fraction, at temperatures rather below the respective boiling point at ambient pressure. The available literature reports a number of experimental and theoretical investigations that suggest the formation of $(\mathrm{EtOH})_{\mathrm{n}} \cdot\left(\mathrm{H}_{2} \mathrm{O}\right)_{\mathrm{m}}$ ring clusters that change the hydrogen bond network and/or favor intermolecular hydrophobic hydration. The decamer, $(\mathrm{EtOH})_{9} \cdot \mathrm{H}_{2} \mathrm{O}$, could be responsible for the peculiar MW susceptibility of the azeotropic mixture.
\end{abstract}

Keywords Water-ethanol $\cdot$ Azeotrope $\cdot$ Microwave heating $\cdot$ Molecular clusters

\section{Introduction}

This paper is a critical reedition (with data and figures updated to the current standards and including not published results) of a 25 year old congress communication [1] (that remained someway hidden to most chemists and physicists). The work, originally aimed to provide some fundament to the common practice of comparing the heating rate in a given product, and in a sample of pure water during 2450MHz MW thawing/cooking food products, and/or preparing concentrated essential oils [2, 3]. The liquid water-ethanol binary seemed a simple model system, since ethanol tends to flash off, as do many aromas from food products, during the MW heating, and can exemplify the competition between different compounds that are susceptible to 2450-MHz MW.

However, the unexpected evidence of a prevailing heating rate, reached by the mixture with azeotropic composition $\left(w_{\mathrm{EtOH}}=96 \%\right.$, or $X_{\mathrm{EtOH}}=0.90 \mathrm{~mol}$ ratio $)$, addressed the interest to more fundamental questions, leaving to a future analysis, an adequate interpretation of the experimental finding.

Alberto Schiraldi

alberto.schiraldi@unimi.it

1 Department Food Environment Nutrition Sciences (DeFENS), Università Di Milano, Milan, Italy
The present work therefore reexamines the old data and provides some tentative interpretation taking into account the studies appeared in the 25 year meanwhile. The simple check of the raising temperature produced by a MW irradiation leads to conclusions in agreement with spectroscopy and molecular dynamics studies. This finding suggests that this approach may be of help in preliminary investigations on new materials, including novel food products, allowing a tentative ranking of their MW susceptibility.

\section{General considerations}

The susceptibility of a material to MW depends on the dissipation factor, namely, the ratio between dielectric loss factor $\left(\varepsilon^{\prime \prime}\right)$, and dielectric constant $\left(\varepsilon^{\prime}\right)$ of the material: $\varepsilon^{\prime}$ reflects the energy stored within the material, because of the polarization induced by the MW electric field, while $\varepsilon^{\prime \prime}$ deals with the energy dissipated as heat. The effect of each component of the dissipation depends on the MW frequency, $\varepsilon^{\prime \prime}$ prevailing above $900 \mathrm{MHz}$ [4], while the attenuation factor of the electric field, $\alpha$, and the penetration depth depend on $\left(\varepsilon^{\prime \prime} / \varepsilon^{\prime}\right)$ [5]. The conversion of electromagnetic to thermal energy is related to the alignment of either intrinsic or induced molecular dipoles and ionic compounds by flip-flop rotations and 
forward-backward molecular displacements, respectively, that can transfer energy to neighboring molecules, no matter whether these are MW sensitive or not. As a result, the overall internal energy of the system raises up and so does its temperature.

This is why a rough way to "measure" the effect of MW irradiation is the detection of the resulting heating rate, $(\mathrm{d} T / \mathrm{d} t)$, [5]. If the power of the MW emitting source is $P_{0}$, then the heating rate produced in a closed system is:

$\frac{\mathrm{d} T}{\mathrm{~d} t}=\dot{T}=V \frac{P_{0} \exp (-2 \alpha z)}{\rho C_{\mathrm{p}}}$

where $\alpha, z, V, \rho$ and $C_{\mathrm{p}}$ are the MW attenuation factor, the depth from the exposed surface, the sample volume, the sample density and its specific heat capacity, respectively.

The attenuation factor depends on the MW frequency [5]. Since water is practically ubiquitous in many agro-products and their derivatives, the selected MW frequency for domestic ovens is $2450 \mathrm{MHz}$ ( $915 \mathrm{MHz}$ in northern and southern America), namely, a frequency at which water shows a very favorable dissipation factor. In the standard practice of food technologists, it is of help to compare the behavior of a MW susceptible compound, $\mathrm{C}$, to the behavior of water, $\mathrm{W},[6,7]$,

$R=\frac{\dot{T}_{\mathrm{C}}}{\dot{T}_{\mathrm{W}}}=\frac{\rho_{\mathrm{W}} C p_{\mathrm{W}} \exp \left(-2 a_{\mathrm{C}} z\right)}{\rho_{\mathrm{C}} C p_{\mathrm{C}} \exp \left(-2 a_{\mathrm{W}} z\right)}$

\section{Materials and methods}

Deionized distilled water and pure ethanol (Merck) were used.

$15 \mathrm{~g}$ samples of water-ethanol mixtures of various composition $(20,40,60,80,96 \mathrm{EtOH} \% \mathrm{w} / \mathrm{w})$ were exposed for $90 \mathrm{~s}$ to the microwaves in a properly designed oven (ALM 1600, SFAMO, Plombières, France), the source power being adjusted at 100 Watt. The samples were contained in $25 \mathrm{~mL}$ glass open ampoules, settled over the base disk of the oven in positions of ascertained [8] identical irradiation density, as the oven can generate a non-uniform distribution of the microwave E-field inside the metal enclosure. An optical fiber thermocouple, dipped in the sample at $0.5 \mathrm{~cm}$ from the upper surface, allowed the measure of the temperature at $10 \mathrm{~s}$ intervals (see Fig. 1). The maximum temperature reached never exceeded $50^{\circ} \mathrm{C}$.

Heat capacity data reported in the previous work [1] gave a qualitative view (with respect to the best literature standards) of the effect of temperature: the heat capacity of pure water, mildly decreases with increasing $T$, from 20 to $95{ }^{\circ} \mathrm{C}$, while the opposite occurs for $\mathrm{EtOH}$ and the $\mathrm{EtOH}$ rich mixtures.

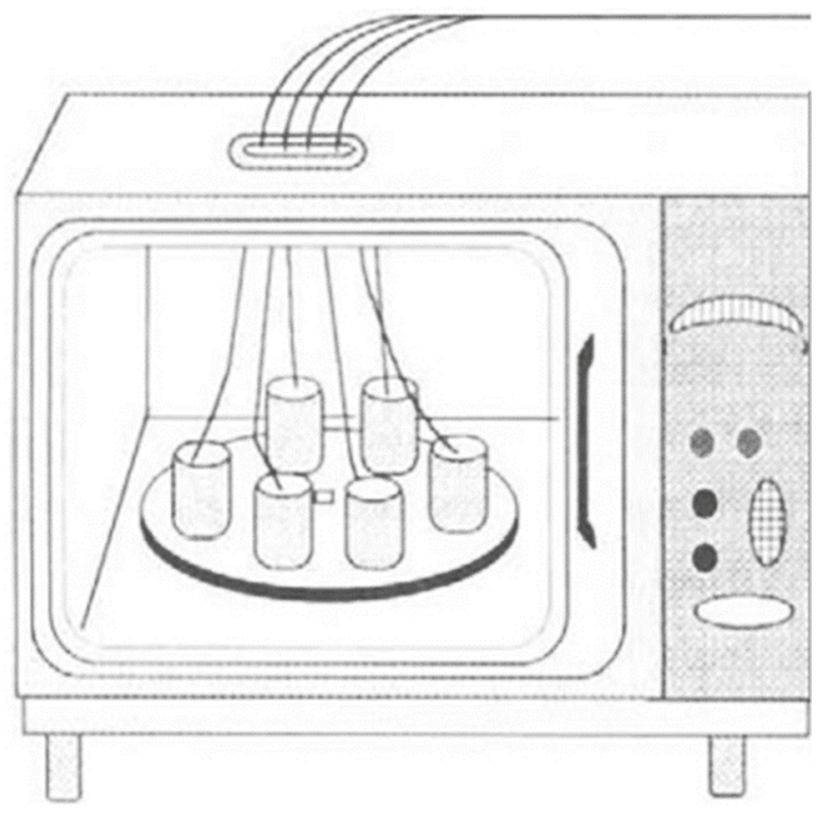

Fig. 1 MW oven. $25 \mathrm{~mL}$ glass beakers settled over the base disk of the oven in positions of ascertained [8] identical irradiation density. The wires represent thermocouples dipped $0.5 \mathrm{~cm}$ from the sample surface

For the scope of the present work, it seemed necessary to use literature data that allow a better definition of the $C_{\mathrm{p}}$ $\left(\mathrm{J} \mathrm{mol}^{-1} \mathrm{~K}^{-1}\right.$ ) trend vs the molar fraction, $X_{\mathrm{EtOH}}$, at constant temperature. Benson et al. [9] reported in a table the values of excess mixing heat capacity, $C_{\mathrm{p}}^{\mathrm{exc}}$, at various molar fraction of water, $X_{\mathrm{W}}$, at $25^{\circ} \mathrm{C}$. The expression $C_{\mathrm{p}}=X_{\mathrm{EtOH}}$ $C_{\mathrm{p}, \mathrm{EtOH}}+\left(1-X_{\mathrm{EtOH}}\right) C_{\mathrm{p}, \mathrm{W}}+C_{\mathrm{p}}^{\mathrm{exc}}$ allows a reliable calculation of $C_{\mathrm{p}}$ at various $X_{\mathrm{EtOH}}$ using the $C_{\mathrm{p}, \mathrm{W}}$ and $C_{\mathrm{p}, \mathrm{EtOH}}$ values [9].

The same treatment allows calculation of the density, $\rho$ $\left(\mathrm{mol} \mathrm{dm}{ }^{-3}\right)$ from data of excess mixing molar volume [10]. Figure 2 shows the $C_{\mathrm{p}}$ and $\rho$ trends.

With the values of the MW attenuation factor of water and ethanol, 0.3 and $0.4 \mathrm{~cm}^{-1}$, respectively [6], the term $\operatorname{exp[-~}$ $2\left(\alpha_{\mathrm{C}}-\alpha_{\mathrm{W}}\right) z$ ] goes from 1 to 0.9 (for $z=0.5 \mathrm{~cm}$ ); it should have a practically straight line trend vs $X_{\mathrm{EtOH}}$, namely, $(1-0.0963$ $X_{\mathrm{EtOH}}$ ), since both $\varepsilon$ ' and $\varepsilon^{\prime}$ ' show this behavior [6].

The ratio $\left[\left(\rho \mathrm{C}_{\mathrm{p}}\right)_{\mathrm{W}} /\left(\rho \mathrm{C}_{\mathrm{p}}\right)_{\mathrm{C}}\right]$, therefore, is the main contribution to $R$ (see Eq. 2).

\section{Results and discussion}

The MW heating experiments led to an unexpected evidence [1]: the azeotropic composition, $w_{\mathrm{EtOH}}=0.96$ mass fraction, reaches the highest temperature after any irradiation time, $t \geq 20$ s. (Fig. 3). 

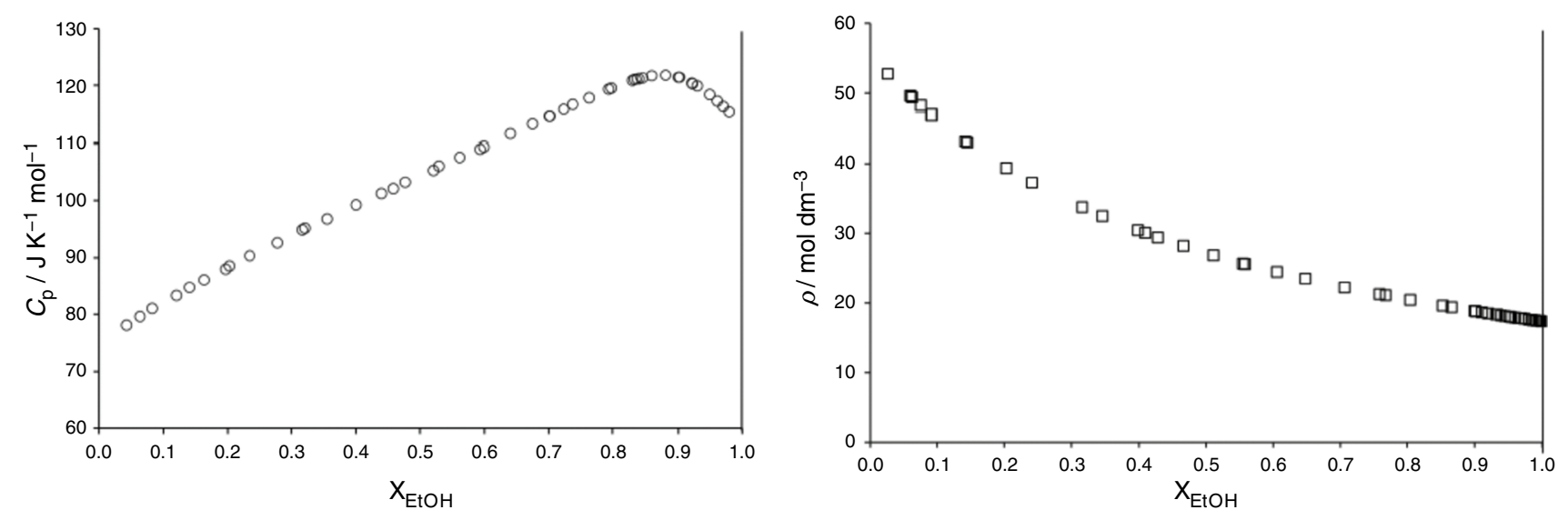

Fig. $2 \mathrm{C}_{\mathrm{p}}$ (on the left) and density, $\rho$ (on the right), vs the ethanol molar fraction, $\mathrm{X}_{\mathrm{EtOH}}$. Data calculated from literature values $[9,10]$ at $25{ }^{\circ} \mathrm{C}$

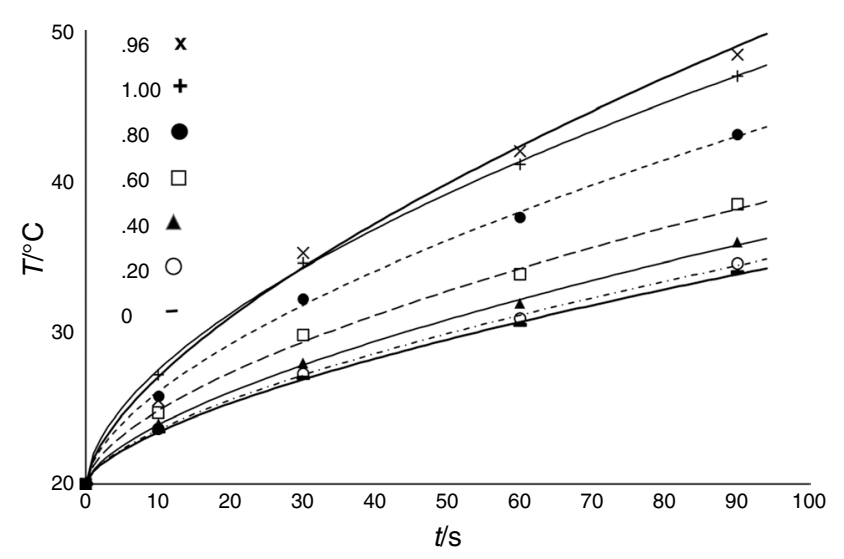

Fig. 3 Temperature records after various MW exposure time for different water-ethanol mixtures. Lettering refers to the relevant $\mathrm{w}_{\mathrm{EtOH}}$ mass fraction

The $T=T(t)$ fits of these data allow determination of the corresponding $\dot{T}=\dot{T}(t)$ trends (Fig. 4). At any $t$, the azeotropic mixture shows the highest heating rate.

Every trace in Fig. 3 shows a steep onset followed by a milder quasi straight-line trend. This behavior depends on the prevailing effect of the microwave radiation: in the early phase of the MW exposure, the absorbed MW energy mainly produces a temperature increase just below the sample surface (about $0.5 \mathrm{~cm}$ beneath the exposed surface, i.e., the location of the thermocouple). Later on, because of the heat transfer toward the core and the surface of the sample, the heating rate of the immediate surroundings of the thermocouple declines. Some withdraw of MW power could also concern the mass loss through evaporation, $\dot{m} \times \Delta_{\text {vap }} H$, although the temperature of every mixture remained largely below the respective boiling point. Both phenomena anyway contribute to reduce the MW heating

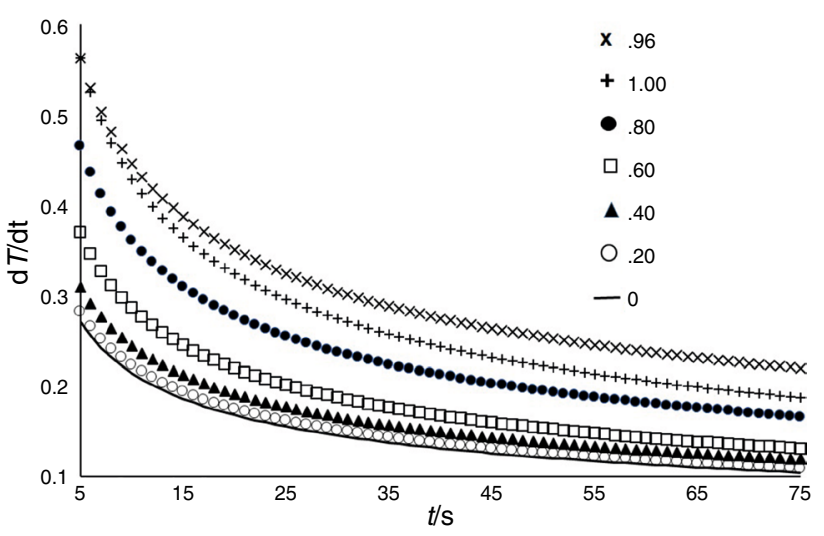

Fig. 4 Heating rate vs the MW irradiation time, $t$, experienced by the water-ethanol binaries. Lettering corresponds to $\mathrm{w}_{\mathrm{EtOH}}$ mass fraction. Curves determined from the fits of the data reported in Fig. 3

effect: this is tantamount to a power dispersion, $P D$, which must be accounted for adjusting Eqs. 1 and 2:

$\frac{\mathrm{d} T}{\mathrm{~d} t}=\dot{T}=V \frac{P_{0} \exp (-2 \alpha z)-P D}{\rho C_{\mathrm{p}}}$

and

$R=\frac{\exp \left(-2 \alpha_{\mathrm{c}} z\right)-(P D)_{\mathrm{C}}}{\exp \left(-2 \alpha_{\mathrm{W}} z\right)-(P D)_{\mathrm{W}}} \times \frac{\rho_{\mathrm{W}} C_{\mathrm{p}, \mathrm{W}}}{\varrho_{\mathrm{c}} C_{\mathrm{p}, \mathrm{c}}}$

Equation 3 states that, for a given $P_{0}$, a large $\dot{T}$ means a small $P D$. $P D$ mainly depends on molecular displacements and collisions enhanced by raising $T$, as during the MW exposure: $T$ raises with $t$, and so does $P D$. This explains the decline of the $\dot{T}$ - $v s-t$ trend (Fig. 4). Since the expected $P D$ in the early phase of the MW heating (low temperature) is much smaller than later on, a rough estimation of 
the $P D$ fraction of the overall adsorbed MW power, $O P$, may be:

$\frac{P D}{O P}=\frac{P D}{P_{0} \exp (-2 \alpha z)} \sim\left(1-\frac{\dot{T}_{\text {final }}}{\dot{T}_{\text {initial }}}\right)$

This fraction is larger than 0.5 (Fig. 5), and seems poorly dependent on the composition, no matter the considered conditions (namely, after a given exposure time, or at a given temperature reached by pure water), save for the azeotropic mixture, which indeed shows values that are significantly (more than the width of the relevant standard deviation) smaller than expected.

A hypothetical bending trend (dotted lines in Fig. 5), shows a tangent, that crosses the straight-line fit of the preceding trend around $X_{\mathrm{EtOH}} \approx 0.90$.

Although, rather qualitative, the above analysis suggests the peculiarity of the azeotropic composition, at temperatures below the relevant boiling point, $78.2{ }^{\circ} \mathrm{C}$.

Evaluation of the ratio $R$ is an alternative way to reach the same conclusion.

Figure 6 reports the $R-v s-X_{\mathrm{EtOH}}$ trend, calculated from the values of the heating rate, reached after $75 \mathrm{~s} \mathrm{MW}$ irradiation. The corresponding temperatures are: 46, 32 and $44{ }^{\circ} \mathrm{C}$, for the azeotropic mixture, pure water and ethanol, respectively.

The $R$ trends, calculated from the values of $\dot{T}$ attained by the mixtures, when the pure water reaches a given temperature, are quite similar (Fig. 7), save for the case of $T_{\text {water }}=22{ }^{\circ} \mathrm{C}$, namely, just after the start of the MW irradiation.

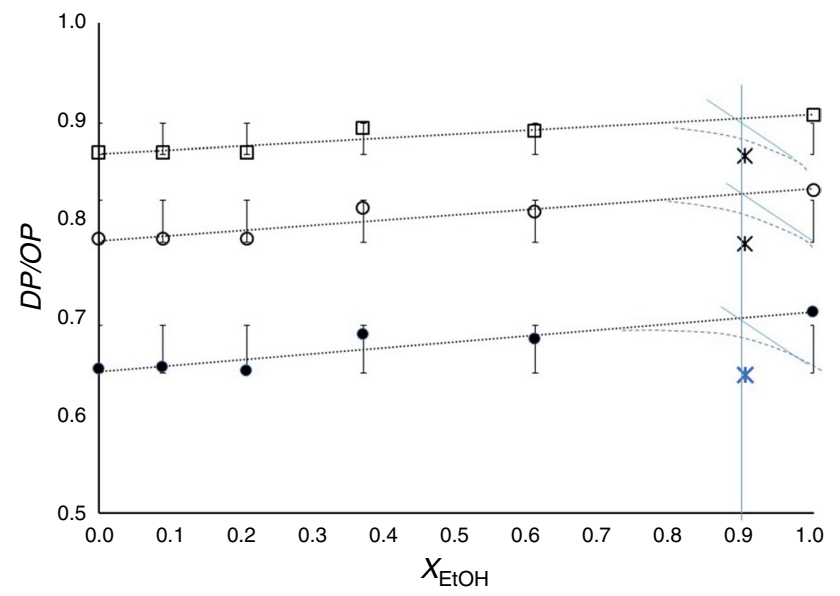

Fig. 5 (Dispersed Power/Overall Power) ratio vs $\mathrm{X}_{\mathrm{EtOH}}$ (Eq. 5), at a given temperature reached by pure water $\left(22{ }^{\circ} \mathrm{C}\right.$, full dots, $25{ }^{\circ} \mathrm{C}$, open circle) and after 75 s MW exposure (open squares). Bars correspond to the standard deviation determined through EXCEL software. The values for the azeotropic composition (stars) are below the straight-line fit for the rest of the composition range
Reminding that the term $\left[\left(\rho \mathrm{C}_{\mathrm{p}}\right)_{\mathrm{W}} /\left(\rho \mathrm{C}_{\mathrm{p}}\right)_{\mathrm{C}}\right]$ is the main contribution to $R$ when $D P$ is negligible, it seems reasonable to compare the $R$ trend with that of $R_{\mathrm{t} \rightarrow 0}$ calculated from the $\dot{T}$ - $v s$ - $t$ trends. Figure 8 shows an acceptable (within the width of the standard error) correspondence for $X_{\mathrm{EtOH}} \leq 0.2$, while a large divergence appears at higher EtOH concentration.

Looking for a qualitative rationale, the $R_{\mathrm{t} \rightarrow 0}$ trend was split evidencing four main ranges, $0<X_{\mathrm{EtOH}}<0.2$, $0.2<X_{\mathrm{EtOH}}<0.5,0.5<X_{\mathrm{EtOH}} \leq 0.9$ and $0.9 \leq X_{\mathrm{EtOH}} \leq 1$, each range being enclosed between the crossing points of the straight line tangents to contiguous ranges (Fig. 8).

Such splitting is in line with the suggestions by Bao et al. [11] and Petong et al. [12[, who recognized two main relaxation ranges, predicting some correspondence with peculiar molecular arrangements. This hypothesis finds a confirmation in a number of theoretical and experimental investigations [13-16] which indeed support the view that

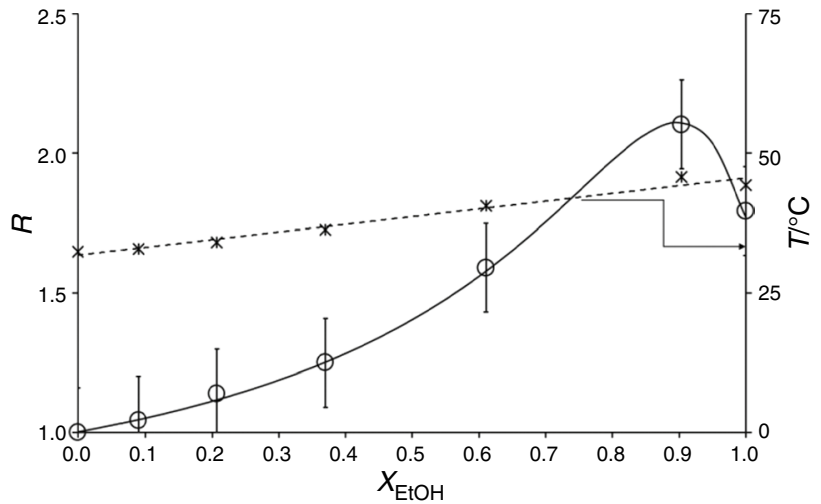

Fig. $6 \mathrm{R}$ versus $\mathrm{X}_{\mathrm{EtOH}}$ for the water/ethanol binaries after $75 \mathrm{~s} \mathrm{MW}$ irradiation. Stars indicate the temperature reached by the relevant mixture. The bars correspond to the standard error determined through EXCEL software

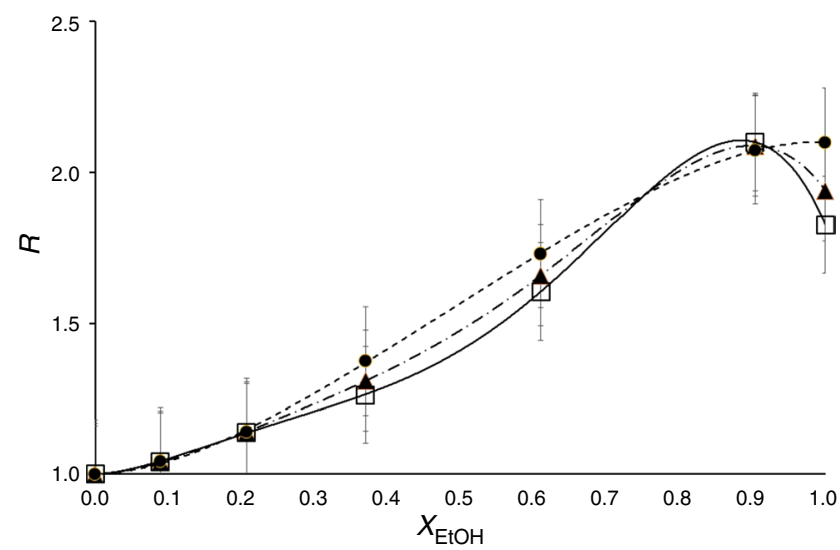

Fig. $7 \mathrm{R}$ trends versus $\mathrm{X}_{\mathrm{EtOH}}$, when pure water reaches $22{ }^{\circ} \mathrm{C}$ (full circles), $25^{\circ} \mathrm{C}$ (full triangles) and $30^{\circ} \mathrm{C}$ (open squares). The bars correspond to the standard error determined through EXCEL software 


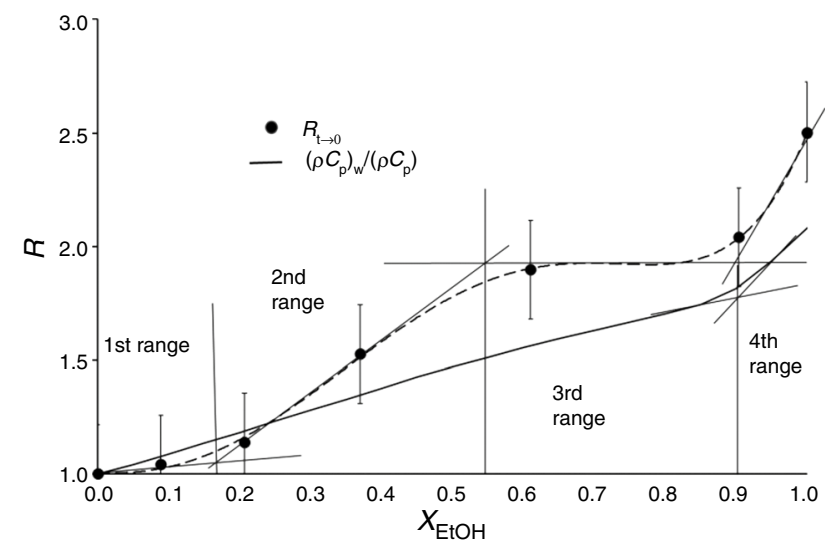

Fig. 8 Comparison of the $\mathrm{R}_{\mathrm{t} \rightarrow 0}$ values (full dots) with the calculated contribution of the $\left(\rho \mathrm{C}_{\mathrm{p}}\right)$ terms in Eq. 2 (continuous line)

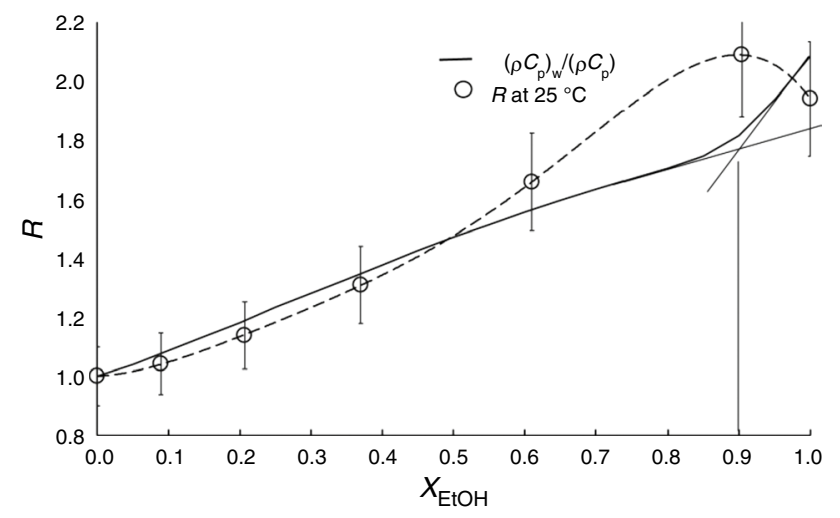

Fig. 9 Comparison of $\mathrm{R}$ at $\mathrm{T}_{\mathrm{W}}=25{ }^{\circ} \mathrm{C}$ (open circles) with the calculated contribution of the $\left(\rho \mathrm{C}_{\mathrm{p}}\right)$ terms in Eq. 2 (continuous line)

the water-ethanol liquid mixtures would change their molecular cluster arrangement (hetero-pentamers, hexamers and eptamers), on varying the composition.

These results show a clear tendency: ethanol - water systems would exhibit a high stability, as the hetero-cluster size approaches the ratio of nine molecules of ethanol and one of water, namely the azeotropic composition. According to molecular dynamics simulations of liquid ethanol-water mixtures [16], hetero-decamers $(\mathrm{EtOH})_{9} \cdot \mathrm{H}_{2} \mathrm{O}$ would indeed appear at the azeotropic composition.

As for this aspects, the analogous comparison with the $R$ trend when the temperature of pure water $T_{\mathrm{W}}=25^{\circ} \mathrm{C}$ shows that the azeotropic mixture has the smallest $D P$, since its $R$ value corresponds to the largest shift from the cross point of the straight-line tangents to the $\left[\left(\rho \mathrm{C}_{\mathrm{p}}\right)_{\mathrm{W}} /\left(\rho \mathrm{C}_{\mathrm{p}}\right)_{\mathrm{C}}\right]$ trend (Fig. 9).

In this case, the contribution of $D P$ (more than $75 \%$ of the absorbed MW power, see Fig. 5), substantially overwhelms the above partition of the $R_{\mathrm{t} \rightarrow 0}$ trend (Fig. 8), but leaves the distinct mark of the lowest $D P$ for the azeotropic mixture
(Fig. 5). If this mixture is the most volatile of the EtOH- $\mathrm{H}_{2} \mathrm{O}$ binary, the $D P$ related to evaporation should be the largest, in disagreement with observations. This means that the low $D P$ value comes from a poor energy transfer toward the core and the surface of the sample, rather than from evaporation. Since such transfer is sustained by molecular displacements, the low $D P$ value could be the result of a heavy molecular arrangement of azeotropic mixture, like that attained with the formation of $(\mathrm{EtOH})_{9}-\mathrm{H}_{2} \mathrm{O}$ decamers [16].

These molecular clusters would be already present at room temperature, involving the whole liquid phase, and persist up to the boiling point that is the lowest of the EtOH$\mathrm{H}_{2} \mathrm{O}$ binary, as they imply weak van der Waals interactions between ethyl groups [16] that are easily loosen on raising $T$. Such interactions are not possible for methanol: this would be why no azeotrope appears in the methanol-water binary [16]. For $X_{\mathrm{EtOH}}>0.90$, the liquid binary would host decamers and more stable molecular arrangements.

\section{Conclusions}

The heating rate, $\dot{T}$, produced in water-ethanol mixtures by a $2450 \mathrm{MHz} \mathrm{MW}$ irradiation depends on the composition, and attains the largest value for the azeotropic composition, at temperatures below the respective boiling point. The ratio $R=\dot{T} / \dot{T}_{\mathrm{W}}$ evidences such peculiarity, as it goes through a maximum for the azeotropic composition, at any temperature from 25 to $50{ }^{\circ} \mathrm{C}$. Taking into account the dissipation of power, $D P$, related to the heat transfer throughout the sample and to the evaporation, the largest heating rate detected for the mixture with azeotropic composition would correspond to the lowest $P D$. This conclusion is in line with the results, reported in the literature on the MW susceptibility of aqueous systems, as the observed behavior would reflect the formation peculiar molecular clusters for the water-ethanol binary with azeotropic composition, even below its boiling point.

Since the experimental approach used in the present work is much easier than a thorough spectroscopic $[11,12]$ or theoretical [13-16] analysis, it may be of help in preliminary investigations on new materials, including novel food products [17], allowing a tentative ranking of their MW susceptibility.

Author contributions The paper is fully prepared by the corresponding author. The name of the co-author Alberto Paoli, was added as he contributed to collect some experimental data for the previous work on the same subject.

Funding Open access funding provided by Università degli Studi di Milano within the CRUI-CARE Agreement. 
Data Availability Data and relevant treatment are fully available on request.

\section{Declarations}

Conflicts of interest The authors declare that they have no conflict of interest.

Open Access This article is licensed under a Creative Commons Attribution 4.0 International License, which permits use, sharing, adaptation, distribution and reproduction in any medium or format, as long as you give appropriate credit to the original author(s) and the source, provide a link to the Creative Commons licence, and indicate if changes were made. The images or other third party material in this article are included in the article's Creative Commons licence, unless indicated otherwise in a credit line to the material. If material is not included in the article's Creative Commons licence and your intended use is not permitted by statutory regulation or exceeds the permitted use, you will need to obtain permission directly from the copyright holder. To view a copy of this licence, visit http://creativecommons.org/licenses/by/4.0/.

\section{References}

1. Paoli A and Schiraldi A (1995) Microwave Heating of water-ethanol mixtures. in food flavors: generation, analysis and process influence. charalambous G editor, Elsevier Science B.V. pp 1065 - 1072.

2. Di Cesare LF, Riva M, and Schiraldi A (1992) Improved retention of mushroom flavor in microwave-hot air drying, in food science and human nutrition. charalambous $G$ editor. Elsevier Science B.V. pp. $249-256$

3. Riva M, Di Cesare LF and Schiraldi A (1993) Microwave and traditional technology to prepare garlic aromatized olive oil. in food flavor ingredients and composition. charalambous $\mathrm{G}$ editor. Elsevier Science B.V. pp. 327 -338.

4. Metaxas AC. microwave heating power eng journal. 1991;5:23747. https://doi.org/10.1049/pe:19910047.

5. Komarov V, Wang S and Tang J (2005) Permittivity and measurements. in encyclopedia of $\mathrm{rf}$ and microwave engineering. Kai Chang editor. Wiley pp 3693 - 3711.

6. Mudgett RE. Microwave properties of heating characteristics of foods. Food Technol. 1986;2:121-35.

7. Mudgett RE, Wang DIC, Goldblith SA. Prediction of dielectric properties in nonfat milk at frequencies and temperatures of interest in microwave processing. J Food Sci. 1974;39:632-5. https://doi.org/10.1111/j.1365-2621.1974.tb00985.x.

8. Riva M, Franzetti L, Mattioli A and Galli A (1993) Microorganism lethality during microwave cooking of ground meat 1 . effect of dishomogeneity of surface power density Ann. Microbiol. Enzymol. 43: 115-129.

9. Benson GC, D'Arcy PI and Kiyohara O (1980) Thermodynamics of aqueous mixtures of nonelectrolytes II. isobaric heat capacities of water- n-alcohol mixtures at $25^{\circ} \mathrm{C}$. J. Sol. Chem, 9(12): 931- 938.

10. Benson GC, and Kiyohara O (1980) Thermodynamics of aqueous mixtures of nonelectrolytes. I. excess volumes of water -n-alcohol mixtures at several temperatures. J. Sol. Chem. 9(10): $791-804$.

11. Bao J-Z, Swicord ML, Davis CC. Microwave dielectric characterization of binary mixtures of water, methanol, and ethanol. J Chem Phys. 1996;104:4441-50. https://doi.org/10.1063/1.471197.

12. Petong P, Pottel R. Kaatze U. J. (2000) Water-ethanol mixtures at different compositions and temperatures. a dieletric relaxation study. Phys. Chem. A. 104: 7420 - 7428.

13. Mashimo S, Umehara T, Redlin H. Structures of water and primary alcohol studied by microwave dielectric analyses. J Chem Phys. 1991;95:6257-60. https://doi.org/10.1063/1.461546.

14. Mejía SM, Espinal JF, Mills MJL, Mondragón F. The role of $\mathrm{OH} \ldots \mathrm{O}$ and $\mathrm{CH} . . \mathrm{O}$ hydrogen bonds and $\mathrm{H} \ldots \mathrm{H}$ interactions in ethanol/methanol -water heterohexamers. J Mol Model. 2016;22:181. https://doi.org/10.1007/s00894-016-3050-9.

15. Wakisaka A, Matsuura K, Uranaga M, Sekimoto T, Takhashi M. Azeotropy of alcohol-water mixtures from the viewpoint of cluster-level structures. J Mol Liquids. 2011;160:103-8. https:// doi.org/10.1016/j.molliq.2011.03.002.

16. Chacón KN, Espinal JF, Montero-Campillo MM, Yáñez M, Mejía SM. Looking for the azeotrope: a computational study of (Ethanol)6-water, (Methanol)6-water, (Ethanol)7, and (Methanol)7 heptamers. J Phys Chem A. 2020;124(35):7080-7. https://doi.org/ 10.1021/acs.jpca.0c05362.

17. McClements DJ, Grossmann L. (2021) The science of plant-based foods: constructing next-generation meat, fish, milk, and egg analogs337.Compr. Rev. Food Sci. Saf. https://doi.org/10.1111/1541412771

Publisher's Note Springer Nature remains neutral with regard to jurisdictional claims in published maps and institutional affiliations. 